\title{
AEROSOL DISTICTIONS OVER JALISCO USING SATELLITE INFORMATION AND GLOBAL MODEL (GOCART): PROSPECTIVE STUDY
}

\author{
Gloria Elena Faus-Landeros ${ }^{1}$, Senior Member, IEEE \\ Ivan E. Villalon-Turrubiates ${ }^{2}$, Senior Member IEEE \\ ${ }^{1}$ UDG Universidad de Guadalajara CUVALLES Ameca Jalisco, México, gloria.faus@itesm.mx \\ ${ }^{2}$ ITESO Universidad Jesuita de Guadalajara Jalisco, México, villalon@ieee.org
}

\begin{abstract}
Aerosols play an important role in global climate change.[Reference new IPCC report]. These particles directly affect the radiative budget due to absorption and scattering of radiation. Additionally, aerosols are known to alter various ecosystems, cloud formation and properties, precipitation, air quality and visibility. They also have well-documented impacts on human health.

In the last 30 years, progress has been made in remote sensing retrievals of aerosol distribution and properties, using different satellite sensors as well as ground-based sun photometer instruments, monitoring programs, and intensive field campaigns around the world. This paper describes how the study and analysis of satellite-based (CALIPSO) measurements and the Global Ozone Chemistry Aerosol Radiation and Transport (GOCART) model make it possible to identify some of the predominant tropospheric aerosols, black carbon and organic carbon. We present the black carbon and organic carbon aerosols and their optical properties by season, within the region of Jalisco México.
\end{abstract}

\section{INTRODUCTION}

While field campaign data have given us some detailed observations of aerosol properties, they do not reveal much concerning particle composition. Likewise, satellite observations give good spatial and temporal coverage, but also do not provide information on particle composition. However, collocated results of chemistry and transport models may be integrated with remote- and in situ sensing of aerosols to try to understand and quantify the temporal and regional aerosol effects. The GOCART model simulates the major tropospheric aerosols types. In this paper we analyze the aerosol optical thickness $\tau$ of the black carbon and organic carbon at $350 \mathrm{~nm}$.

\section{VERIFICATION PROTOCOLS}

We analyze the aerosol optical depth of black carbon and organic carbon from 2003 to 2008 in the Jalisco state of México. This model has a horizontal resolution of $2^{\circ}$ latitude by $2.5^{\circ}$ longitude and 20-30 vertical sigma layers. This model uses the assimilated meteorological fields generated from the GODDARD Earth Observing System Data Assimilation System (GEO DAS). The model provides important information not only of the predominant tropospheric aerosols, but also global distributions of aerosol concentrations, vertical profiles and optical thickness of individual type and total aerosols.

The principal source of black carbon and organic carbon is from biomass burning. Other anthropogenic emissions are from domestic, transportation and industrial combustion (Cooke et.al.1999). Assume 
that $80 \%$ of black carbon and $50 \%$ of organic carbon emissions are hydrophobic, the rest of aerosols being hydrophilic.

The hydrophobic carbonaceous aerosols age becoming hydrophilic in about 1.2 days. The atmospheric lifetime of the carbonaceous aerosols is controlled by dry deposition. Hydrophilic aerosol lifetimes are about 5 days for organic carbon and 6 days for black carbon.

The optical depth is a measurement of the change of the sunlight intensity induced by the presence of the aerosols in the atmosphere. The optical depth is very important for the energy budget.

The aerosol optical thickness can be calculated from modeled size distributions, hygroscopic properties of the aerosols and their complex refractive indices. The GOCART model assumes the organic carbon and black carbon are all submicron aerosols with a maximum radius of $0.5 \mu \mathrm{m}$. The relationship between the aerosol extinction optical thickness $\tau$ and the aerosol mass loading per unit area is wellrepresented by:

$\tau=\frac{3 Q M}{4 p r_{\theta}}$

Where:

$\tau=$ aerosol extinction optical thickness

$M=$ aerosol mass loading per unit area

$\rho=$ particle density

$r=$ the effective radius

$Q=$ the extinction coefficient

Both $\tau$ and $Q$ are wavelength-dependent.

On average, global black carbon and organic carbonare optically thin.However, black carbon and organic carbon play an important role in determining the magnitude of aerosol radiative forcing and the increase in the atmospheric temperature.

We found from the GOCART model measurements about black carbon at $350 \mathrm{~nm}$ that show how the concentration of these particles increased during the spring 2005.
To get a better quantitative comparison, we extract the model GOCART results from the central region of México. These regions are chosen to compare the state of Jalisco specially its principal city Guadalajara, with the big city of México, Ciudad de México both cities are two of the three major polluted regions of the country.

The following table shows the average optical depth per season of a period of six years. Is possible to see how the black carbon optical depth in 2003 was almost the same except during spring season when the optical depth increase more than 3.00E-03. In 2004 the increase during spring wasn't too high. In 2005 the black carbon had the biggest concentration during spring. In 2006 the black carbon optical depths decrease and in 2007 and 2008 were almost the same. The winters had also the biggest value during 2005. During the summers as we can see on the table the optical depth is decreasing and the autumns have almost the same optical depth during the 6 years.

\begin{tabular}{|c|c|c|c|c|}
\hline \multicolumn{5}{|c|}{350 nm Black Carbon optical depth } \\
\hline Year & Winter & Spring & Summer & Autumn \\
\hline 2003 & $6.19 \mathrm{E}-03$ & $9.83 \mathrm{E}-03$ & $6.36 \mathrm{E}-03$ & $6.63 \mathrm{E}-03$ \\
\hline 2004 & $6.64 \mathrm{E}-03$ & $7.03 \mathrm{E}-03$ & $6.02 \mathrm{E}-03$ & $6.33 \mathrm{E}-03$ \\
\hline 2005 & $7.15 \mathrm{E}-03$ & $1.16 \mathrm{E}-02$ & $6.69 \mathrm{E}-03$ & $6.74 \mathrm{E}-03$ \\
\hline 2006 & $6.70 \mathrm{E}-03$ & $8.13 \mathrm{E}-03$ & $6.18 \mathrm{E}-03$ & $6.10 \mathrm{E}-03$ \\
\hline 2007 & $5.98 \mathrm{E}-03$ & $7.92 \mathrm{E}-03$ & $5.86 \mathrm{E}-03$ & $6.11 \mathrm{E}-03$ \\
\hline 2008 & $6.08 \mathrm{E}-03$ & $7.58 \mathrm{E}-03$ & $5.59 \mathrm{E}-03$ & $6.39 \mathrm{E}-03$ \\
\hline
\end{tabular}

Fig.1. Table shows the average optical depth of black carbon at $350 \mathrm{~nm}$ in central region of México, 20032008.

In the next graph is illustrated the average optical depth of black carbon at $350 \mathrm{~nm}$. As we mention is easy to identify the increasing of the optical depth during the spring season each year. Also we can see how the black carbon concentration is almost the same during the autumn with respect the other seasons in all the 6 years. 


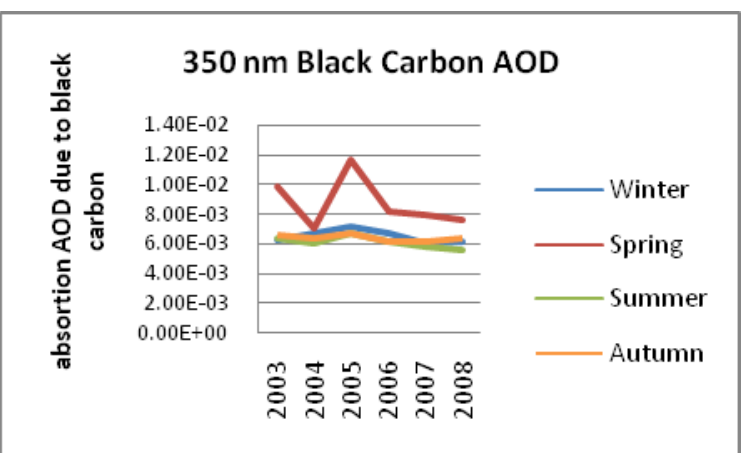

Fig. 2. This graph shows the absortion optical depth due to Black Carbon of the central region of México according to GOCART data.

In the following map of Mexico we can see the concentration of the black carbon. As we can see the predominant concentration of these aerosols are on a big city, Ciudad de México. It is reasonable because the industry and transportation is much bigger than in the others cities of the region is cover. We also can see the red color cover Guadalajara city that is in the state of Jalisco and is reasonable because also exist many industries and transportation activities. If we observe the map, we can see how the concentration decrease in the other smaller states of the region.

As we mention before one of the characteristics of the black carbon is the absorption of the sun light and their effects of temperature increase.

column integrated optical depth due to black carbon at $350 \mathrm{~nm}$

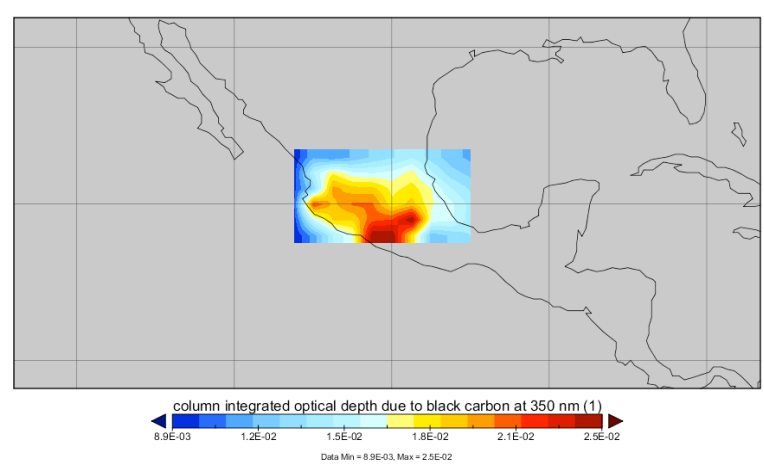

Fig.3. In this map you can see how the black carbon aerosols cover the major states of the central region of México. This region includes two of the biggest cities: Guadalajara in Jalisco state and Ciudad de México, during May 2005.
The next graph illustrates the average optical depth of organic carbon at $350 \mathrm{~nm}$. It is easy to identify the increasing of the optical depth during the spring season each year. Also we can see how the organic carbon during the summer do not change to much each year. Here the aerosols concentration during the autumn have a different behavior. If we compare with the black carbon the concentration in 2006 decrease with respect the other years. Anyway the biggest concentration of the organic carbon are during the spring seasons and also during 2003 and 2005 existed a big difference with respect the other years.We can notice during the last three years the concentration has almost the same value except autumn season.

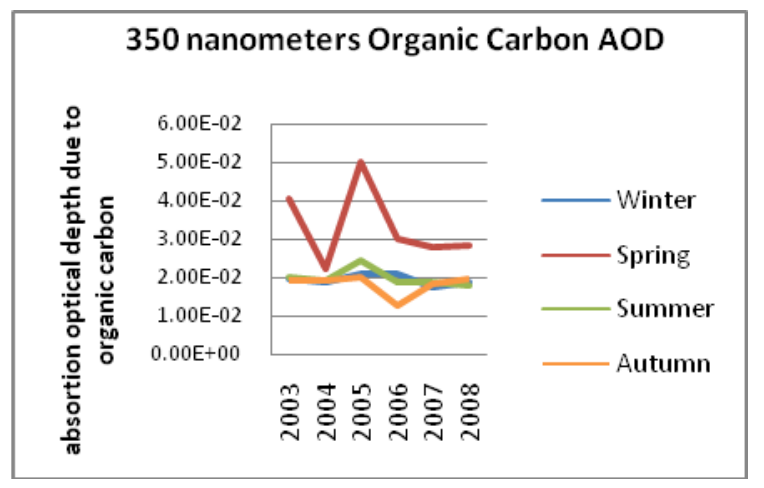

Fig. 4. This graph shows the absorption optical depth due to Organic Carbon of the central region of México according to GOCART data.

In the following map of México we can see the concentration of organic carbon. As we can see the predominant concentration of these aerosols are also on the big cities like Ciudad de México and Guadalajara, Jalisco. The industry and transportation activities on these cities are much bigger than in the others regions of the zone. It is important to mention that the organic carbon has the capability to absorve the sun light and their effects are the atmosphere temperature increase. 


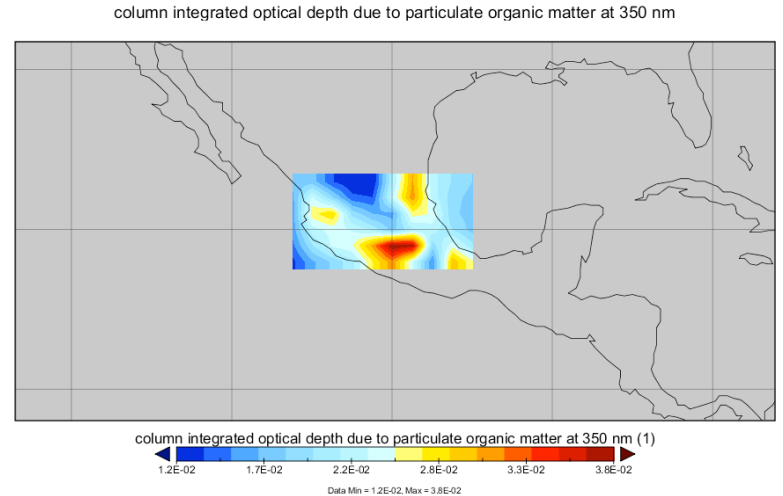

Fig. 5. This figure shows the organic carbon aerosols are more predominant over Ciudad de México and we can see a significant concentration of these particles on Jalisco state, May 2005

\section{CONCLUDING REMARKS}

We studied the temporal and regional distribution of black carbon and organic carbon aerosols optical depth in and around central Mexico. The principal objective was analyzed the seasonal variation of $350 \mathrm{~nm}$ black carbon and organic carbon aerosols in Jalisco state. The information gave us the optical depth absorption of these particles and how they are concentrated in Guadalajara city of Jalisco; the other regions of the state are not really affected by these particles. These results will be the basis of future investigations related to environmental and atmospheric processes in this region.

\section{REFERENCES}

[1] Tomas F. Stocker, et al., "Intergovernmental Panel on Climate Change (IPCC) Fifth Assessment Report (AR5) Working Group 1: The Physical Science Basis," 2013. Available at: $\mathrm{http}: / /$ www.ipcc.ch/report/ar5/wg $1 /$ mindex.shtml

[2] Holben, B., et al., 2001, "An emerging ground-based aerosol climatology: Aerosol Optical Depth from AERONET," J. Geophys. Res., 106 (D11), 12,067-12,097, doi:10.1029/2001JD900014 (http://www.agu.org/pubs/crossref/2001/2001JD 900014.shtml).

[3] "Intergovernmental panel of climate change" (IPCC) report., 2013 (http://www.ipcc.ch/report/ar5/wg1/\#.UtR15E2x4 QQ)

[4] Mian Chin., et al..,2001 "Tropospheric Aerosol Optical Thickness from the GOCART Model and Comparisons with Satellite and Sun Photometer Measurements"

[5] Mishchenko, M.I., et al., 2004, "Monitoring of aerosol forcing of climate from space: analysis of measurement requirements," J. Quant. Spec. Rad. Trans. 88 (1), 149-161, doi: 10.1016/j.jqsrt.2004.03.030. (http://www.sciencedirect.com/science/article/pii /S0022407304001360)

[6] NASA's Cloud-Aerosol lidar and Infrared Pathfinder, CALIPSO (n.d) http://www.nasa.gov/mission_pages/calipso/mai $\mathrm{n} /$ (retrieved 2011/12/31).

[7] Thomas M.Lillesand, R. W. (2007). Remote Sensing and image interpretation. United States of America: Wiley. 